\title{
Resorption of Spermatozoa in the Sperm Duct of Rainbow Trout during the Post-Spawning Period
}

\author{
Roland BILLARD ${ }^{* 1}$ and Fumio TAKASHIMA ${ }^{* 2}$ \\ (Accepted July 13, 1982)
}

\begin{abstract}
Preliminary investigations on the loss of spermatozoa in the sperm duct of rainbow trout during the post-spawning period showed that the spermatozoa degenerated in sifu in the duct lumen or were phagocytized there by free phagocytes and by the epithelial cells. Drastic alterations occurring in the epithelium between March and April were characterized by excretory activity in March and intensive phagocytic activity in April when the process of sperm release had nearly stopped. A possible relation between the structural and functional changes in the sperm duct and endocrine balance were discussed.
\end{abstract}

In salmonid males, the duration of spermiation and sperm release (liberation of the spermatozoa from the testicular lobules and the sperm duct, respectively) is usualy longer than the period of ovulation in the females. Spermatozoa are found in the testis and sperm duct of rainbow trout males for a few months after the normal spawning season which usually occurs during late autumn and early winter. In some conditions, especially in captivity, the process of spermiation stops and a large amount of spermatozoa ( 50 to $80 \%$ ) remains in the genital tract. $^{1,2)}$ When the next spermatogenetic cycle starts in May-June, the remnant of spermatozoa from the previous cycle has disappeared, indicating that sperm resorption occurs during the spring. This has been shown in the testis where the spermatozoa are actively phagocytized by Sertoli cells and macrophages (phagocytes) present in the lumen of the lobules of several species: rainbow trout, ${ }^{1}$ ) Sebastes $^{3)}$ and stickleback. ${ }^{4}$ The resorption of spermatozoa has also been observed by light microscopy in the sperm duct of some salmonid species $^{4-7)}$ and sea bass. ${ }^{8)}$ In the present study, electron microscopical investigations were carried out on the resorption and the degenerescence of spermatozoa in the sperm duct of rainbow trout during the post-spawning period.

\section{Materials and Methods}

Adult males with an average body weight of $160 \mathrm{~g}$ were taken in March and April from the
Forgeot fish farm. All the fish showed signs of sperm release; the GSI ranged between 6 and $12 \%$. The fish were at the end of the first reproductive cycle, the normal spawning period of the females in this population being December-January. The males, which were kept apart from the females, were brought to the laboratory a few days before autopsy. They were anesthetized in $0.2 \% \mathrm{MS}-222$; the sperm was sampled after stripping and its volume measured. The spermatocrit was measured by the technique similar to the leukocrit of $\mathrm{MC}$ LEAY and GoRDON ${ }^{0}$ (12000 rpm for $15 \mathrm{~min}$ ). The animals were then killed by decapitation and the free part of the sperm duct between the testis and the genital papilla was removed. Some fraguments of the median part were taken, immersed and dissected out in small pieces in $3.3 \%$ glutaraldehyde solution with a phosphate buffer ( $\mathrm{pH} 7.25$ ). Fixation was carried out in this medium followed by post-fixation in $2 \%$ osmium solution in the same buffer. Pieces were embedded in epon, cut into ultrathin sections and stained with uranyl acetate and then lead citrate for $5 \mathrm{~min}$ and covered with a carbon film. In some cases, glutaraldehyde fixation was followed by embedding in glycolmethacrylate and the sections were treated for $30 \mathrm{~min}$ with phosphotungstic acid in $1 \%$ aqueous solution in normal $\mathrm{HCl}$. Electron microscopic observations were carried out on 3 males each month, and the sperm volume and spermatocrit were determined on 7 males each month.

*1 Laboratory of Fish Physiology, National Institute of Agronomical Research, 78350, Jouy-en-Josas, France (フランス国立農学研究所).

*2 Laboratory of Fish-Culture, Tokyo University of Fisheries, Konan 4-5-7, Minato, Tokyo 108, Japan (東 京水産大学). 


\section{Results}

In March, the spermatocrit was $25 \pm 4.3 \%$ (mean \pm S.D.) and spermatozoa were consistently found in the lumen of the duct. The epithelial cells lining the sperm duct did not show much phagocytic activity (Figs. 1, 2), but their morphology varied considerably among males and even in the same sperm duct. In some cases, the epithelium was columnar with only a few cellular debris in the lumen (Fig. 1); in other specimens, the epithelium was squamous with sort of granules of secretion surrounded by a membrane which were found inside the cells and in the lumen along with other cellular debris. These granules were seemed to originate from the epithelial cells, suggesting a kind of apocrine secretion (Fig. 2). The membranes delimiting two adjacent cells were highly folded (Fig. 1), and connected by apical junctions. The nuclear envelop was folded and the nucleus was located near the basal part of the cell close to the basement membrane (Fig. 1). These epithelial cells showed some pinocytic activity. The spermatozoa present in the lumen presented early signs of degeneration such as swelling of the plasma membrane on the head. The chromatin often appeared to be slightly disaggregated. In the lumen, isolated cells showed high phagocytic activity with numerous sperm heads in the cytoplasm at various stages of resorption (Fig. 3).

In April, the epithelial cells of the sperm duct showed high phagocytic activity. Remnants of the sperm head (Fig. 4) as well as various lysosomelike and residual bodies (Figs. 5, 6). were identified in the cytoplasm. The lumen of the sperm duct was filled with cellular debris and degenerating sperm heads (Fig. 7). The spermatocrit (15.0土 $4.9 \%$ was significantly $(p<0.05)$ lower than in March.

In March, and to a lesser extent in April, we identified an intermediate "cloudy" area between the seminal fluid and the spermatozoa in the spermatocrit tube. This area represented the accumulation of cellular debris and degenerating sperm heads and phagocytes. The process of sperm release was much more active in March $(2.86 \pm 1.1 \mathrm{~m} /)$ than in April $(0.44 \pm 0.91 \mathrm{~m} l)$ when only very small quantities of sperm were collected $(p<0.005)$.

\section{Discussion}

The spermatozoa present in the sperm duct during the post-spwaning period undergo active phagocytosis and resorption. Two different types of degenerescence were successively identified: (i) phagocytosis by the epithelium of the sperm duct and by isolated cells in the lumen, and (ii) lysis of spermatozoa in situ in the duct lumen, starting with slight disaggregation of the chromatin which was progressively reduced to small filaments. In March, phagocytosis seemed to be carried out mainly by isolated cells and, later in April, the spermatozoa were phagocytized by the epithelial cells of sperm duct or they degenerated in the lumen of the sperm duct. The intensity of this resorbent process may be estimated by the "cloudy" area observed at the limit of the seminal fluid and the spermatozoa in the spermatocrit tube. Phagocytes have been identified in the lobules and the efferent duct system of brook trout ${ }^{\mathrm{s})}$ and rainbow trout. ${ }^{\text {) }}$ In case of the latter it is suggested they are Sertoli cells detached from the lobule wall. HENDERSON ${ }^{\text {s) }}$ also indicated that the phagocytes found in the sperm duct may also originate in the lobules. WeISEL ${ }^{10)}$ also found that the diameter of the duct lumen in trout increased slightly in post-spawning fish.

Important changes occur in the epithelial cells of the sperm duct. Secretory granules seem to be actively secreted in the lumen of the duct but their significance is not known. Such granules were also reported in the seminal fluid of the sperm duct in Astyanax mexicanus. ${ }^{11)}$ The sperm duct, with the Sertoli cells, probably contributes to the secretion of the seminal plasm which is essential to spermatozoon survival in vitro. Spermatozoon survival is shorter when the sperm is deprived of seminal plasma, ${ }^{*}$ and proteins have been shown to have a protective effect on spermatozoa. ${ }^{12)}$ It remains to be determined if this secretory activity is constant during the whole spermiation period. Between March and April, the structure of the epithelial cells is changed considerably by active phagocytosis when the process of sperm. release has considerably declined. Annual changes in some enzymatic activities, especially those of phosphatase which increase from January to June, have been reported in the epithelium of the sperm duct by HURK. ${ }^{\text {) }}$

Important endocrine changes in Gth and androgens occur at the beginning and the end of the spermiation process ${ }^{13,14)}$; these may be connected with the structural and functional alterations in the sperm duct. These endocrine changes, usually

* R. Billard (unpublished). 
correlated with the process of spermiation, may also affect sperm survival. Work is in progress to elucidate the changes in the sperm duct (during the period of spermiation) as they are related to hormonal alterations and experimental modifications in the endocrine balance.

\section{Acknowledgements}

We wish to thank Mr. SCANDOLo for making the micrographs and Ms. DaIfuku for the English translation of the manuscript. FT was on sabbatical leave from the Tokyo University of Fisheries. We thank Dr. J. F. EleCHon for the critical reading of the manuscript.

\section{References}

1) R. Billard, B. Breton, and B. Jalabert: Ann. Biol. anim. Bioch. Biophys, 11, 190-212 (1971).

2) R. BILlard: Bull. Fr. Pisc., 253, 139-149 (1974).

3) T. SASAKI and T. Igarashi: Bull. Fac. Fish.,
Hokkaido Univ., 25, 100-106 (1974).

4) S. M. Ruby and D. B. MCMillan: J. Morph., 131, 447-466(1970).

5) N. E. Henderson: Can. J. Zool., 40, 631-641 (1962).

6) R. Van Den Hurk, J. A. J. Vermeiu, J. Stegenga, J. Peute, and P. G. W. J. Van Oordr: Ann. Biol. anim. Bioch. Biophys., 18, 899-904 (1978).

7) R. Van Den, Hurk, J. Peute, and J. A. J. VermeIJ: Cell Tiss. Res., 186, 309-325 (1978).

8) I. HAYASHI: Jap. J. Ichthyol., 16. 68-76 (1969).

9) D. J. MCLeay and M. R. Gordon: J. Fish. Res. Board Can., 34, 2164-2175 (1977).

10) G. F. Weisel: J. Morph., 73, 207-229 (1943).

11) P. Rasquin and E. HAfTer: J. Morph., 89, 397402 (1951).

12) R. Billard: Rev. Can. Biol. 40, 317-321 (1981).

13) M. Sanchez-Rodriguez, A. M. Escaffre, S. MARLot, and P. ReINAUd: Ann. Biol. anim, Bioch. Biophys., 18, 943-948 (1978).

14) A. Fostier, R. Billard, B. Breton, M. Legendre, and S. Marlot: Gen. Comp. Endocrinol., 46, $428-435$ (1982).

\section{Explanations of Figures}

Fig. 1. Epithelial cells from the sperm duct of a spermiating rainbow trout male in March. $\times 12000$ bm: basement membrane; cd :cellular debris; $g$ : various granules; $L$ : duct lumen; Ip: lipid droplets; $N$ : nucleus; $S$ : swelling of the plasma membrane of the sperm head ( $\mathrm{sp}$ ); $\mathrm{Z}$ : zona occludens.

Fig. 2. Squamous epithelial cell from the sperm duct of a rainbow trout in spermiation in March. $\times 12000$, Same abbreviations as Fig. 1 .

Fig. 3. Isolated cell found in the lumen of the sperm duct of a male rainbow trout in spermiation in March. $\times 10000$. Same abbreviations as Fig. 1. Spd: sperm head in degenerative changes.

Fig. 4. Sperm head (spd) and various residual bodies in resorption in the epithelium of the sperm duct of rainbow trout in April. $\times 16000$.

Fig. 5. Various residual bodies in an epithelial cell of the sperm duct of rainbow trout in April $\times 20000$

Fig. 6. Epithelial cell of the sperm duct of a rainbow trout with various lysosome-like and residual bodies. $\times 15000$

Fig. 7. Degenerating sperm head in the lumen of the sperm duct of rainbow trout in April. $\times 16000$ 


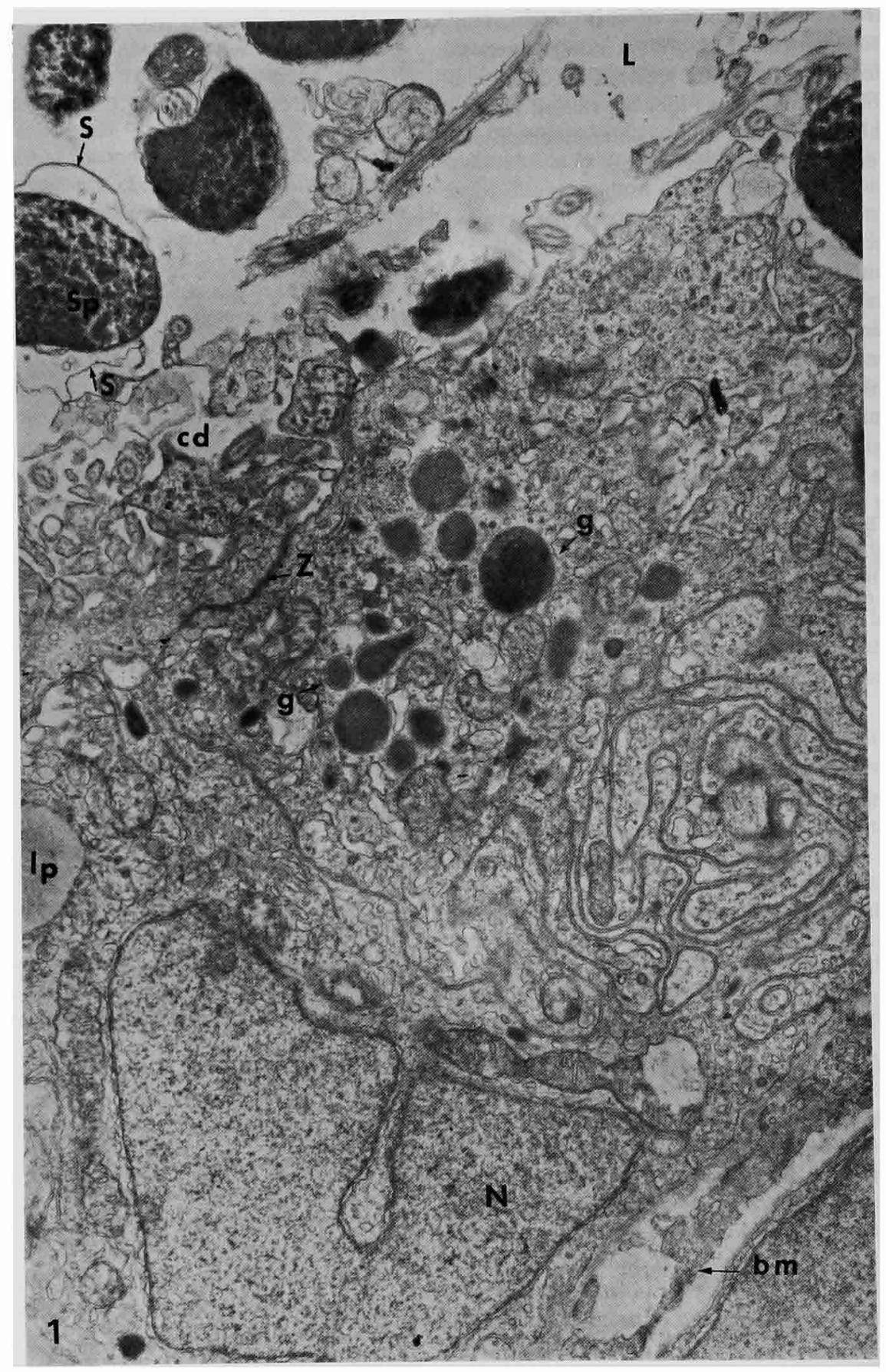




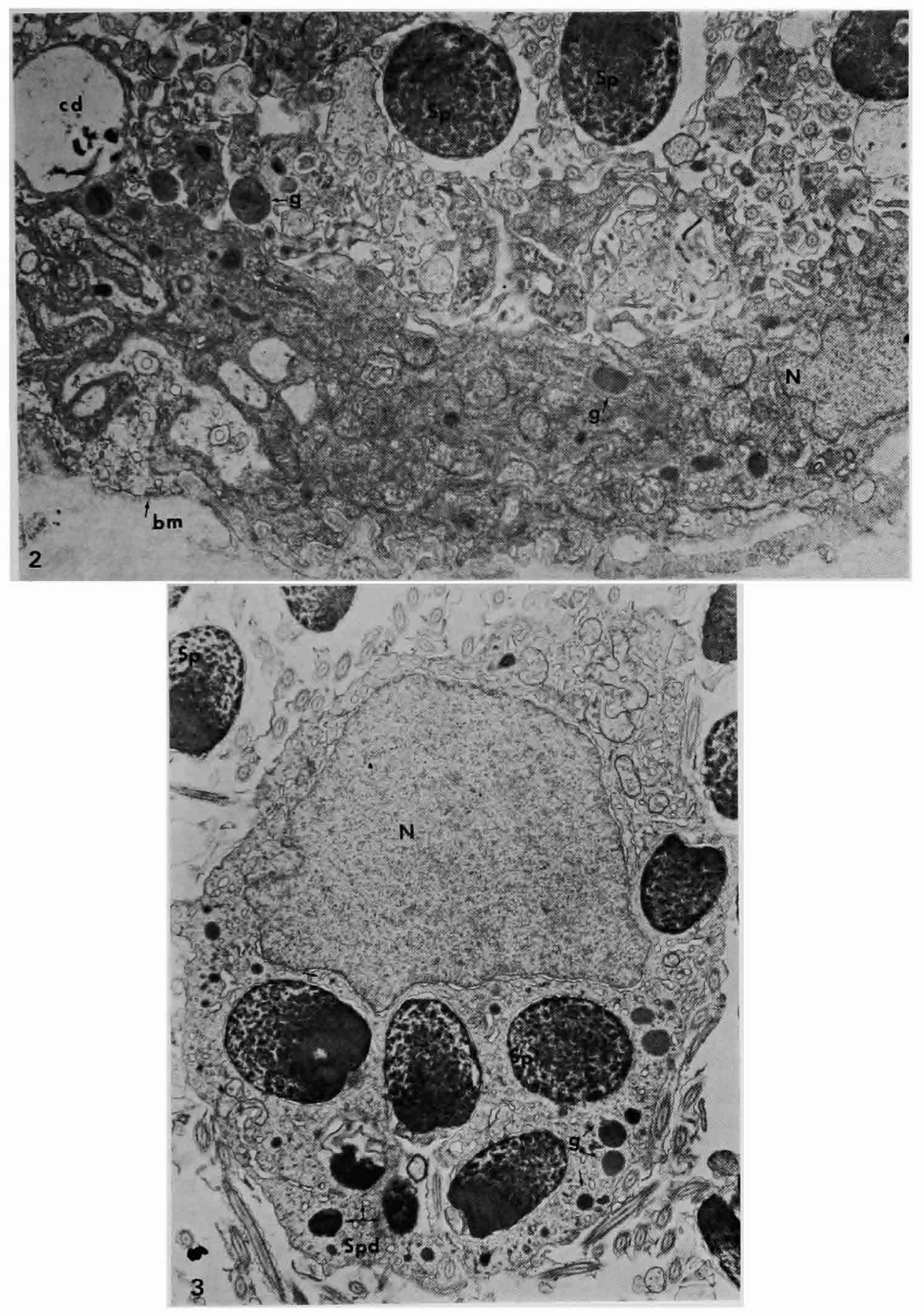



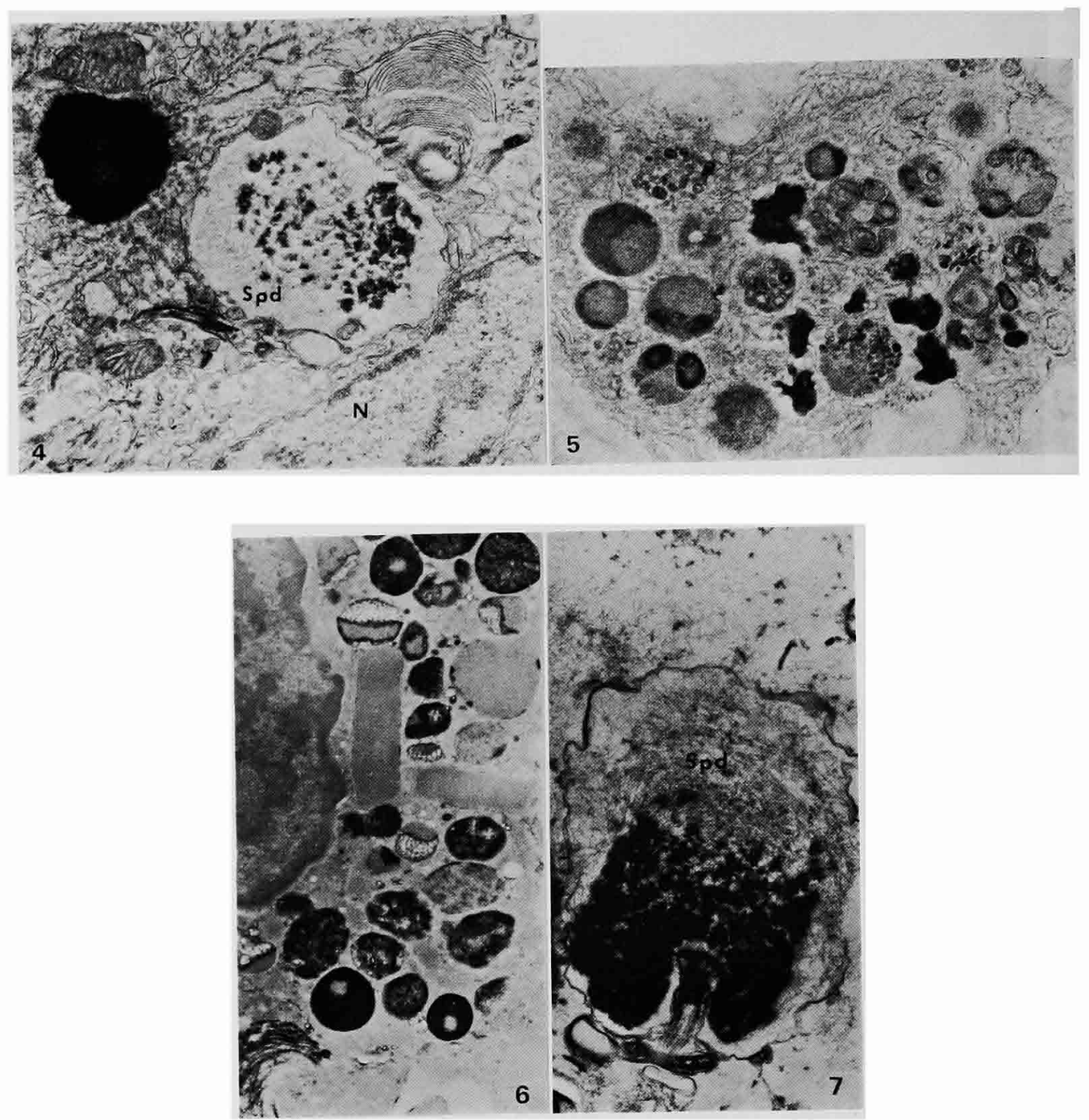